\title{
Numerical investigation on enhancement of heat transfer using rod inserts in single pipe heat exchanger
}

\author{
S. H. Raheemah ${ }^{1}$, M. Ashham ${ }^{1 *}$, K. Salman ${ }^{1}$ \\ ${ }^{1}$ Department of Mechanical Technical /Production, Al kut Technical Institution, \\ Middle Technical University, Baghdad, Iraq \\ *Email: ashham.a4@gmail.com
}

\begin{abstract}
The current study focused on statistically investigating nanofluids' turbulent flow and rate of heat transfer in double pipe heat exchanger with rod inserts. Through the use of numerical simulation, the effects which the various kinds of nanofluids have on the enhancement of heat transfer using finite volume method (FVM) are studied. An application of homogeneous heat flux is made to the tube wall. More so, an examination of the effect of three varying slant angles of rod insert $\left(\alpha=25^{\circ}, 30^{\circ}, 45^{\circ}\right)$ was carried out at varying Reynolds number ranging from 7500 - 20000. The statistical results revealed that the coefficient of transferring heat in the tube containing rod inserts is higher than that of the smooth tube. In addition, results also showed that when rod insert are used in double pipe heat exchanger to augment the Nusselt number increases the slant angle. The max value of Nusselt number was demonstrated at the angle $45^{\circ}$ of rod insert. Through the use of the rod inserts at $\left(\alpha=45^{\circ}\right)$ and ( $\mathrm{S}=30 \mathrm{~mm}$ ), the coefficient of maximal skin friction was determined because of the resistance of larger flow. The maximal value of the Performance Evaluation Criteria (PEC) was mentioned in the case of min slant angle of $\left(\alpha=25^{\circ}\right)$ and the pitch distance of $S=30$ $\mathrm{mm}$.
\end{abstract}

Keywords: Hybrid nanofluids; thermal conductivity; temperature; ethylene glycol; titanium oxide; zinc oxide.

\section{INTRODUCTION}

In the last decades, the improvement of heat transfer in a two-pipe heat exchanger has received great attention from researchers. A heat exchanger is described as a device through which heat is transferred between one or more fluids. In order to stop the fluids from mixing or having direct contact with each other, a solid wall may be used in separating them. The role of heat transfer enhancement cannot be underestimated, because it enhances the mixing of fluid for the purpose of increasing the criteria of performance evaluation of the devices used in transferring heat. It also helps in improving the thermal system's efficiency. The rate of heat transfer between fluids and the heat exchangers' wall have been enhanced through the use of various techniques of heat transfer. The purpose of this enhancement is to enable the conservation of energy, decrease the cost and size of heat exchangers. An example of one of the techniques used is the passive method of heat transfer enhancement. In the passive method, various elements are included with the aim of generating swirl and vortex flow, 
which in turn increases the coefficient of heat transfer. Through the use of numerical and experimental methods, the effects that the different kinds of insert elements in tube has on the enhancement of heat transfer have been studied. Such methods include, V-finned tape inserts, conical-strip inserts, vortex-generator VG inserts, coil inserts, louvered strip inserts, twisted tapes inserts, hollow twisted tapes, butterfly inserts, Helical screw-tape inserts, perforated circular disk inserts, small rod insert and perforated plate inserts, helical tape inserts, wire coil and twisted tape inserts. The use of different methods of heat transfer methods have been employed in heat exchanger, and such methods have been enhanced and widely applied in engineering applications and industrial equipment like solar thermal systems, petrochemical industry, car radiator, power plant, air-conditioning, chemical reactors, refrigeration, process industry, shell-and-tubes heat exchangers, nuclear reactor, etc. In the study carried out by [1] numerical method was used in studying how conical strip inserts affect the performance of thermo hydraulic in the tubular turbulent laminar flow zone. Results of their study showed that the average Nusselt number of the tube which was improved by $3.7-5.51$ times $\{\mathrm{Nu}=16.15-24.05$ average $\}$, and an increase in average factor of friction by $5.31-14.77$ times ( $f=0.59-1.51$ average) of plain tube occurred. By means of numerical simulation, Fan et al. [2] carried out an investigation of the attributes of flow resistance, heat transfer and general performance of turbulent flow in terms of thermohydraulic within a circular shaped tube consisting of fitted louvered strip inserts. The findings of their study revealed that the augmentation of the number OF Nusselt occurred by $2.75-$ 4.05 times $(\mathrm{Nu}=108.71-423.87)$ as in the case of smooth tube. There was a change in value range of Performance Evaluation Criterion (PEC) to 1.60 - 2.05. In a research carried out by [3], an experiment was carried out to with the aim of investigating the effect of inserted louvered strips on the transfer of heat and features of friction in a central tube of heat exchanger. Findings of their study showed that increases occurred in friction loss and Nusselt number by $413 \%$ and $284 \%$ for the forward louvered strip, respectively, while the increases for the backward louvered strip over the plain were $233 \%$ and $263 \%$, respectively. A statistical study carried out by [4] examined how the thermodynamic and thermal performance of the receiver of a parabolic trough collector is affected by inserts of perforated plate. Their results showed that increase occurred in the modified thermal efficiency by 1.2 $\%$ and $8 \%$.

Similarly, in an experiment carried out by Guo et al. [5], the impact of decrease in conical-strip tube inserts' upwind area on characteristics of turbulent friction factor of turbulent flow and heat transfer was studied. These researchers found that conical-strip inserts had a Nusselt number of $53 \%$, while that of the inserts of conical-ring was $56 \%$. More so, an experiment was carried out by Azari and Derakhshandeh [6] with the aim of studying how the performance of heat exchanger is influenced by the use of Nanofluids and butterfly tube inserts (BTI). Their results indicated that the Nusselt was reasonably improved by about $345 \%$ at $0.027 \% \mathrm{NVC}$ and $R e=1500$ for the tube flow alongside its BTI relative to the tube. Also, increasing has been recorded about $2.5 \%$ in the NVC of their study, which reduced the Nusselt number for the flow inside the tube with butterfly tube inserts. In a numerical investigation which was carried out by [7], the affection of the use of louvered strip inserts that were put into a heat exchanger for the circular pipe and flow field using nanofluids of different kinds was studied. Based on their statistical results, heat transfer could be improved by the arrangement of the forward louvered strip at the max slant angle at $\alpha=$ $30^{\circ}$ by approximately $367 \%$ to $411 \%$ and min pitch of $\mathrm{S}=0.3 \mathrm{~mm}$. They also reported that 
the (PEC) value was within the range of $1.28-1.56$. In a numerical an experimental study conducted by [8], the effect which the various types of butterfly inserts, jagged and classic twisted tape has on the transfer of heat, thermal efficiency and friction factor of an air-cooled heat transfer was investigated. The findings indicated that the butterfly insert with inclined angle of $90^{\circ}$ achieved the highest level of thermal efficiency. In order to determine the effect of pipe insert on reduced pressure, transfer of convection heat and Performance Evaluation Criterion (PEC), [9] conducted a numerical study, and the findings of the study revealed that improvement occurred in the max Nusselt number by 3.4 - 10.3 like that of the smooth tube. The effect which coiled wire inserts placed in turbulent flow regime has on decrease in pressure and transfer of heat in a tube was examined [10]. They were able to achieve an overall enhancement of $50 \%$, and the Reynolds number of the coiled wire with $\mathrm{P} / \mathrm{D}=1$ and $\mathrm{s}=1 \mathrm{~mm}$ was found to be 4220. In another experimental study carried out by Garc1' et al. [11], the effect of three wire coils of varying pitch placed within a smooth tube in transition and laminar regimes was investigated. Using different Reynolds, they studied pressure drop and transfer of heat under conditions of heat flux. Their findings revealed that an increase occurred in the friction factor by about $5 \%$ and $40 \%$ in the completely laminar region. When [12] numerically simulated the effect of a novel tube insert known as centrally hollow narrow twisted tape, they discovered that the overall tube performance of the insert improved by $28.1 \%$. A new method that involves the use of a twisted tape was introduced [13] as a means of predicting the coefficient of heat transfer during the boiling of flow within horizontal tubes. A numerical study was carried out by Rios-Iribe et al. [14] with the aim of studying the effect which a twisted tape has on the transfer of a non-Newtonian fluid with a steady laminar regime flow via a circular tube. Their results of experiment results revealed that with a decrease in the ratio of twist and an increase in $\mathrm{Re}$, an increase occurred in the thermohydraulic efficiency. In another study in which [15] conducted an experimental and a numerical analysis, the effect which inserts of longitudinal strip has on the thermal hydraulic attributes of the flow of air within a circular tube was studied. Their results showed that increases in the coefficient of pressure drop and heat transfer of tubes with inserts of twisted tape occurred by $13-61 \%$ and $150-370 \%$, respectively.

The effect of V-finned tapes (DFT) on the enhancement of thermal performance in a stable heat fluxed inserted square duct was studied [16]. Their numerical and experimental study showed that the maximum friction factor and heat transfer were achieved by the inserted square duct at $\mathrm{RB}=0.20$ and $\mathrm{RP}=0.50$, and the maximum thermal performance was achieved at $\mathrm{RB}=0.1$ and $\mathrm{RP}=1.5$. The effect which triple helical tapes placed in a tube for turbulent flow via a tube has on the enhancement of heat transfer, was studied by Bhuiya et al. [17]. A maximum enhancement of 3.7 was achieved for the inserts as per constant blower power. When [18] examined the conical rings affection on the enhancement of heat transfer and change in pressure drop within a pipe with stable heat flux, they found that the impact which the conical ring inserts had on the efficiency of improvement of heat transfer in the heat exchangers was adverse. In an experimental study [19], a rectangular-cut twisted tape was inserted in a tube, and its effect on coefficient of transfer of heat, friction factor, and the efficiency of heat transfer of water for turbulent flow was investigated. It was found that efficiencies of heat transfer enhancement were around the range of 1.9 to 2.3. More so, it was found that the efficiencies increased as the Reynolds number increased. Similarly, a $30^{\circ} \mathrm{V}$ shaped rib was inserted in a tube, and its effect on the enhancement of heat transfer was studied in an experimental study carried out [20]. The findings of their study showed that a 
max thermal improvement factors of about 1.4 and 1.09 were got for the ribbed twisted tape at $\mathrm{BR}=0.09$ and the twisted tape without rib, respectively. The current study focuses on studying the numerical effect of a rod inserted in a double pipe heat exchange on the coefficient of heat transfer and friction factor. More so, the effect of PEC on varying rods inserts inclination angles $\alpha$, of $25^{\circ}-45^{\circ}$ with $\operatorname{pitch}(\mathrm{S}=30 \mathrm{~mm})$ is examined respectively in this study. In the study, the use of Reynolds numbers ranging from 7500 to 20000 is employed.

\section{PHYSICAL MODEL AND ASSUMPTIONS}

\section{Physical Model}

Figure 1. below is a schematic diagram that represents the circular tube in which the rod is inserted. The rod insert has a length of about $6 \mathrm{~mm}$. The current study also investigates the effect of varying mixtures of the slant angle $\left(\alpha=25^{\circ}, 35^{\circ}, 45^{\circ}\right)$ and pitch, $\mathrm{P}(\mathrm{P}=30 \mathrm{~mm})$. The tube has an inner diameter of $\mathrm{D}=20 \mathrm{~mm}$, and a length of $\mathrm{L}=400 \mathrm{~mm}$. In the study, attention is not given to the thickness of solid wall.

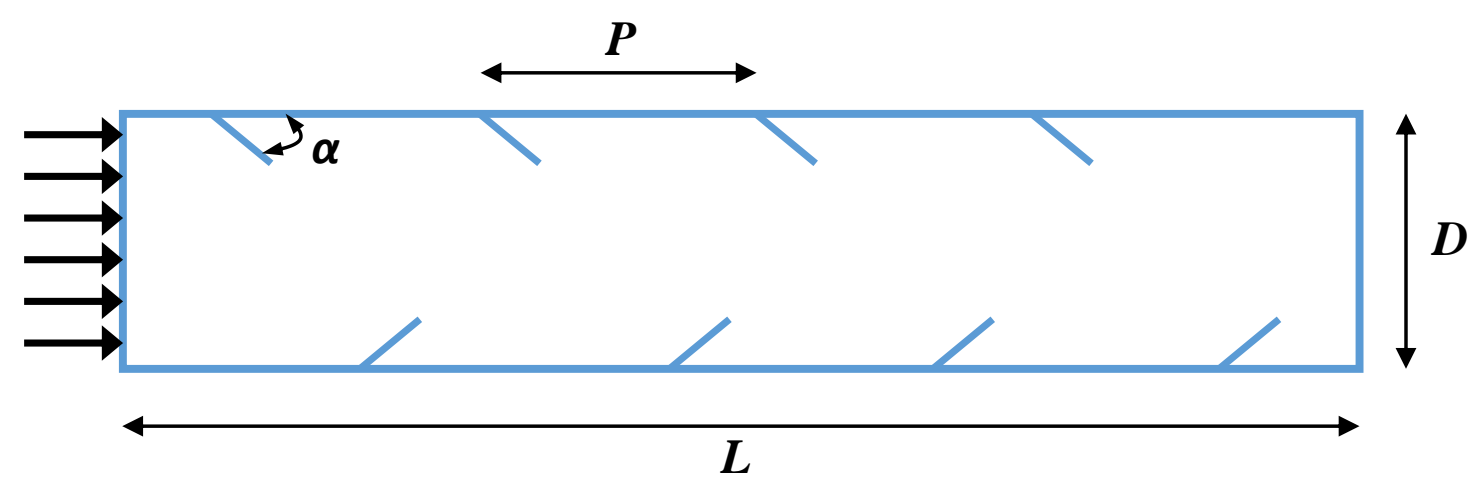

Figure 1. Schematic representation of a circular tube containing rod inserts.

\section{Governing Equations}

Continuity, energy and momentum equations for flow of fluid in single pipe heat exchanger in which rod are inserted, were solved using CFD analysis. The phenomenon which is investigated in this study is governed by the following equations; incompressible and 2dimensional equations for the Navier-Stokes and energy equations as given below.

Continuity equation:

$$
\partial / \partial x\left(\rho u_{i}\right)=0
$$

Momentum equation:

$$
\frac{\partial\left(\rho u_{i} u_{i}\right)}{\partial u_{i}}=-\frac{\partial p}{\partial x_{j}}+\frac{\partial}{\partial x_{i}}\left[\mu\left(\frac{\partial u_{i}}{\partial x_{j}}+\frac{\partial u_{j}}{\partial x_{i}}+\right)\right]-\frac{2}{3} \mu \frac{\partial u_{k}}{\partial x_{k}} \delta_{i j}
$$

Energy equation:

$$
\frac{\partial}{\partial x_{i}}\left(\rho u_{i} C_{p} T-k \frac{\partial T}{\partial x_{J}}\right)=u_{i} \frac{\partial p}{\partial x_{j}}+\left[\mu\left(\frac{\partial u_{i}}{\partial x_{j}}+\frac{\partial u_{j}}{\partial x_{i}}\right)-\frac{2}{3} \mu \frac{\partial u_{k}}{\partial x_{k}} \delta_{\mathrm{ij}}\right]
$$


where, $C_{p}$ denotes the particular heat at constant pressure, $(\mathrm{Kj} / \mathrm{kg} . \mathrm{k}), \mathrm{k}$ represents the turbulent kinetic energy $\left(\mathrm{m}^{2} / \mathrm{s}^{2}\right)$, $\varepsilon$ represents the turbulent dissipation rate $\left(\mathrm{m}^{2} / \mathrm{s}^{2}\right)$. Since, $\mathrm{k}-\varepsilon$ approach has several applications in heat transfer because of several reasons such as it is clearly solved by CFD for planar shear layers as well as recirculating flows [22], therefor it has been considered in this study. Many researchers have stated that this model is widely employed and validate turbulence model with applications ranging from industrial to environmental flows $[23,24]$. The $\mathrm{k}-\varepsilon$ approach represents in the follow equations.

$$
\frac{\partial}{\partial x_{i}}\left(\rho k u_{i}\right)=\frac{\partial}{\partial x_{j}}\left[\left(\mu+\frac{u_{t}}{\sigma_{k}}\right) \frac{\partial k}{\partial x_{j}}\right]+G_{k}-\rho \varepsilon
$$

Likewise, the TKE rate of dissipation, $\varepsilon$ is given by the following equation:

$$
\frac{\partial}{\partial x_{i}}\left(\rho \varepsilon u_{i}\right)=\frac{\partial}{\partial x_{j}}\left[\left(\mu+\frac{u_{t}}{\sigma_{k}}\right) \frac{\partial \varepsilon}{\partial x_{j}}\right]+C_{1 \varepsilon} \frac{\varepsilon}{k} G_{k}-C_{2 \varepsilon} \rho \frac{\varepsilon^{2}}{k}
$$

where, $G_{k}$ denotes the TKE generation rate, while $\rho \varepsilon$ represents the rate of destruction. $G_{k}$ is written as:

$$
G_{k}=\left(-\overline{\rho u_{\imath} u_{j}}\right) \frac{\partial u_{j}}{\partial x_{i}}
$$

PEC was significant in the evaluation of the quality of the heat transfer enhancement of heat exchanger. PEC is given as:

$$
\operatorname{PEC}=\left(N u / N u_{\circ}\right) /\left(f / f_{\circ}\right)^{1 / 3}
$$

Where Nusselt numbers of improved tube and smooth tube are denoted by $N u$ and $N u_{\text {。 }}$, respectively. The factors of friction of the smooth tube and improved tube are represented by $f$ and $f_{\circ}$, respectively.

\section{Boundary Conditions}

In the currents study, the conditions of boundary for the physical domain are simplified as demonstrated in Figure 1. The figure illustrates the single pipe heat exchanger in which the rod is inserted, alongside an application of the uniform heat flux on the bottom and top walls, while the left and right sides are subjected to velocity inlet and pressure outlet, respectively. An application of a heat flux of $100,000 \mathrm{~W} / \mathrm{m}^{2}$ is made to the bottom and top walls of the heat exchanger. Selections of the (RNG) $k-\varepsilon$ turbulence and standard $k-\varepsilon$ turbulence models were made with the aim of achieving prediction accuracy in the circular tube. To solve the equations of time independent incompressible Navier-Stokes, and to perform the analysis of turbulence model, the use of finite volume model was employed. The use of pressure-velocity coupling algorithm Semi Implicit Method for Pressure-Linked Equations (SIMPLE) was employed in the evaluation of the pressure field. A completely developed velocity profile was used at the inlet with a turbulence intensity of $1 \%$ maintained. Study results in terms of the effect of slant angle of rod inserts on Nusselt number, performance evaluation criteria and coefficient of skin friction are presented. In the simulation conducted in this study, the use of water was employed as working fluid for the numerical investigation which was conducted in the heat exchangers containing rod inserts. The placements of the inclined rod inserts was done in the tube of the test that possessing with slant angles, $\alpha$ of $25^{\circ}, 35^{\circ}$ and $45^{\circ}$ with the linear direction 


\section{Grid Independent Test}

In this study $\mathrm{RE}=15000, \mathrm{P} / \mathrm{D}=0.5$ has been considered to set mesh. Based on the outcomes, it is seen that, the $\mathrm{Nu}$ is proportionate to the number of faces, and the $\mathrm{Nu}$ was 170 when number of faces was 250000 . Moreover, there is no change in $\mathrm{Nu}$ when number of faces increasing to 260000 and up as shown in Figure 2. Thus 260000 faces was configured to execute simulation process

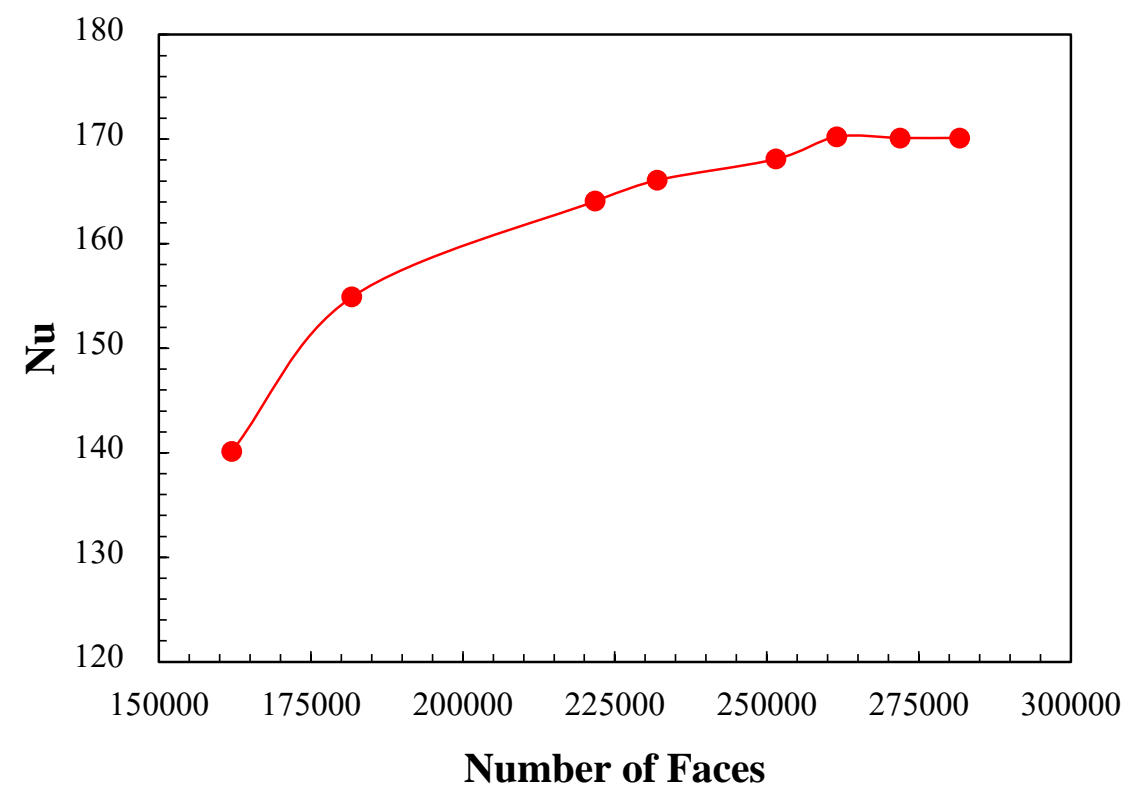

Figure 2. Grid independent study.

\section{Code Validation}

One of the essential steps taken in numerical studies to ensure that the numerical codes are valid as in other past studies is code validation. The process of code validation also helps in preparing the code for runs. The method of code validation used in Fan et al. [2] was employed in this study for the purpose of validating code. This group of researchers numerically examined impact of inserted conical strips on the Nusselt number within a circular tube as presented in Figures 1. More so, they also used air as a test fluid to examine the effects of the conical strips' geometrical parameters. The results of the comparison carried out in this study between the present study results and that of Fan et al [2] are presented in Figure 3. It can be observed that the result of the current study supports the results of Fan et al. [2]. The results has been verified with experimental results and the average percentage of error is $8 \%$ and this percentage is acceptable to proceed simulation process [21] 


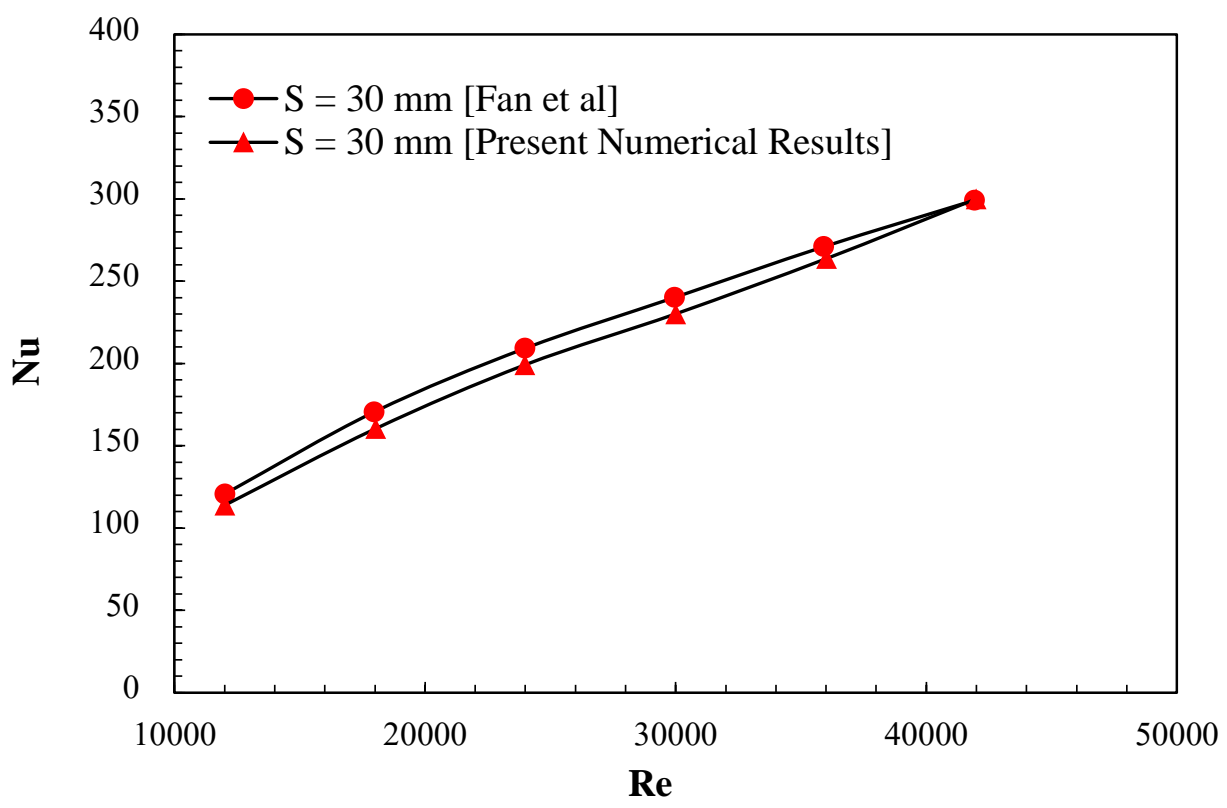

Figure 3. Present results comparison with the result of Fan et al. [2] with pitch $\mathrm{S}=30 \mathrm{~mm}$.

\section{RESULTS AND DISCUSSION}

\section{Effect of Geometrical Parameters}

In Figure 4, variation of Nusselt number with Reynolds number for smooth pipe and pipes with insets at various angles. Based on the results of the study, as the Reynolds number increases, the Nusselt number for all inclination angles of the rod inserts increases. It was also observed that an increase in the slant angle causes to the Nusselt number to also increase with maximum value achieved at angle $45^{\circ}$. In addition, it was also found that a strong intensity of turbulence was produced by the rod inserts. This in turn caused the flow to mix up rapidly, particularly at high slant angles. The enhancement of heat exchanger is clearly mentioned in the results that shown in Figure 3. The results show that the enhancement of heat exchanger is $60 \%$ compared with smooth pipe when use inserts with $25^{\circ}$. Furthermore, the enhancement of heat exchanger was $62.5 \%$ compared to the smooth pipe when use inserts with $35^{\circ}$ and maximum enhancement occurs when inserts with angle $45^{\circ}$ is used and it is $65.7 \%$ compared to the smooth pipe. The reason of increasing percentage in enhancement with increasing of inserts angles is that the increasing the angle of inserts is causing obstruction in the flow of the fluid. 


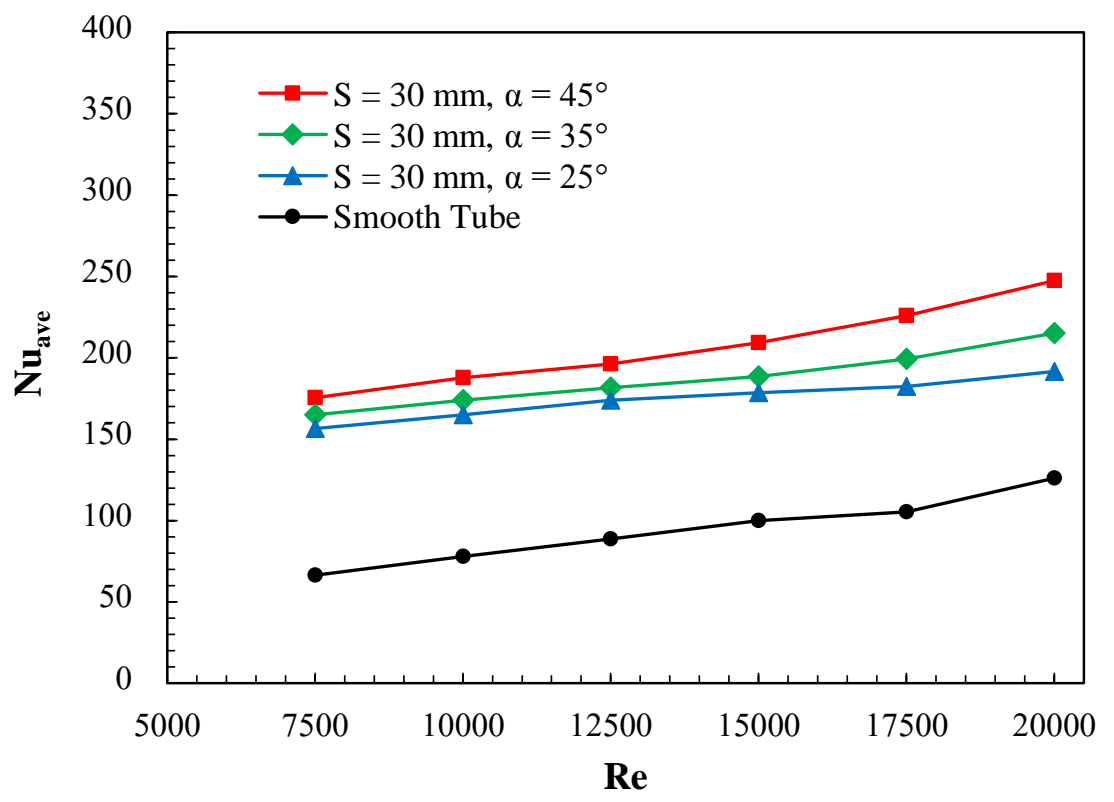

Figure 4. Reynolds number with a different of the Nusselt number with angles $\quad S=30 \mathrm{~mm}$ of the inserts.

Figure 4 illustrates the variation of skin friction coefficients with Re for smooth tube and tubes with different rod insert angles. From the figure, it can be clearly observed that as the Reynolds number increases for all inclination angles of the rod insert, a decrease occurs in the coefficient of skin friction. Furthermore, as the slant angle of rod inserts increases, an increase occurs in the coefficient of skin friction with a max value achieved at the angle of $45^{\circ}$ due to the resistance of larger flow which was observed at the largest angle. The results shown Figure 5 represents that the coefficient of skin friction is increase with increase of slang angle. The coefficient of skin friction increase $20 \%$ compared to the smooth pipe when the angle of inserts is $25^{\circ}, 50 \%$ increase when the angle of inserts is $35^{\circ}$ and $66.6 \%$ increase when the angle of inserts is $45^{\circ}$. 


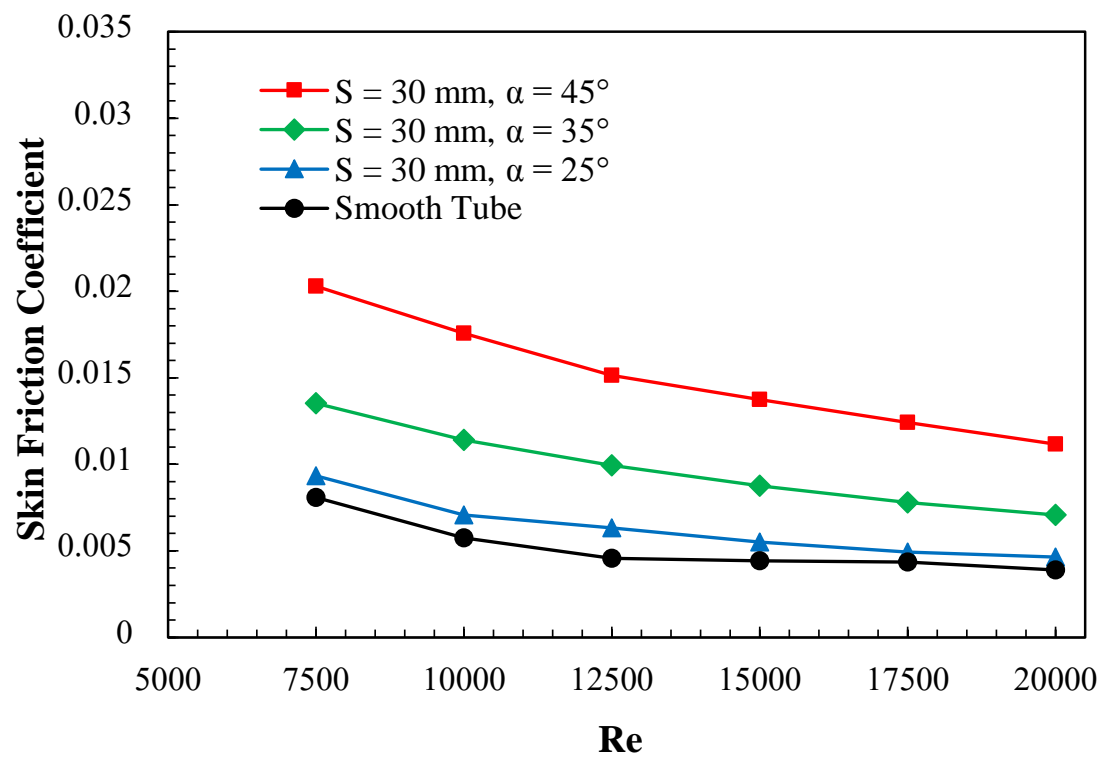

Figure 5. Varying coefficient of friction $t$ with Reynolds number with varying angles and $\mathrm{S}=30 \mathrm{~mm}$ of rod inserts.

Figure 6 presents the data used in the comparison of the effect of varying slant angles of rod inserts on the PEC. From the figure, it can be observed that the use of a small slant angle ( $\alpha$ $\left.=25^{\circ}\right)$ at pitch $(\mathrm{S}=30 \mathrm{~mm})$ with small Reynolds number can be employed so as to achieve a better value of PEC.

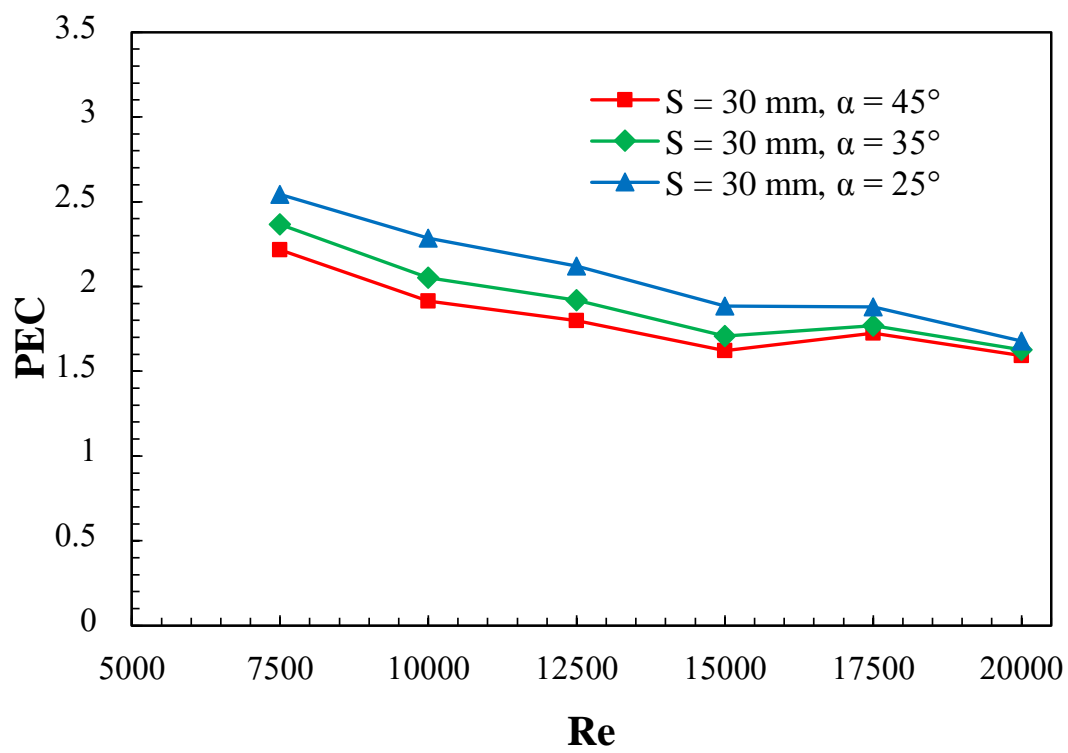

Figure 6. PEC with Reynolds number with varying angle of slant and at $\mathrm{S}=30 \mathrm{~mm}$ of rod inserts.

The effect which the various slant angles of rod inserts has on the temperature contours and velocity were at $\operatorname{Re}=7500$ as contained in Figure 7. From the figures, it can be seen that the 
high turbulence flow or vigorous blending at the back of the rod inserts leads to many vortices, which increase as the slant angle increases. The maximum vortices and mixing flow were achieved at the max angle $\left(\alpha=45^{\circ}\right)$. It was found that the weakest flow was at the smallest angle $\left(\alpha=25^{\circ}\right)$, thereby resulting in a convective current that is too weak, with limited effect on the rate of heat transfer.
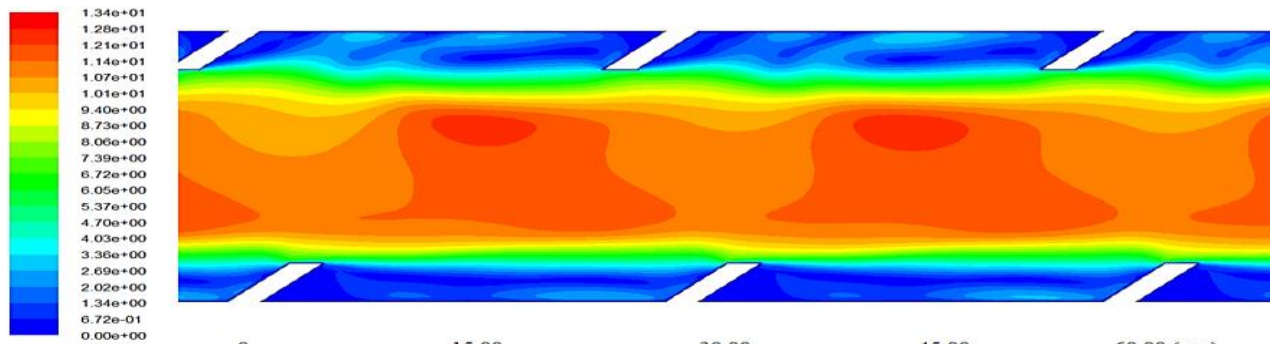

$6.720-01$

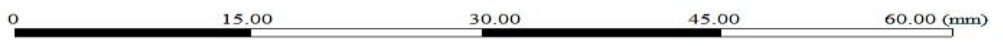

$4.319+02$
$4.24+02+02$

$4.18++02$
$4.118+02$

$4.110+02$
$4.050+02$
$3.030+02$
3
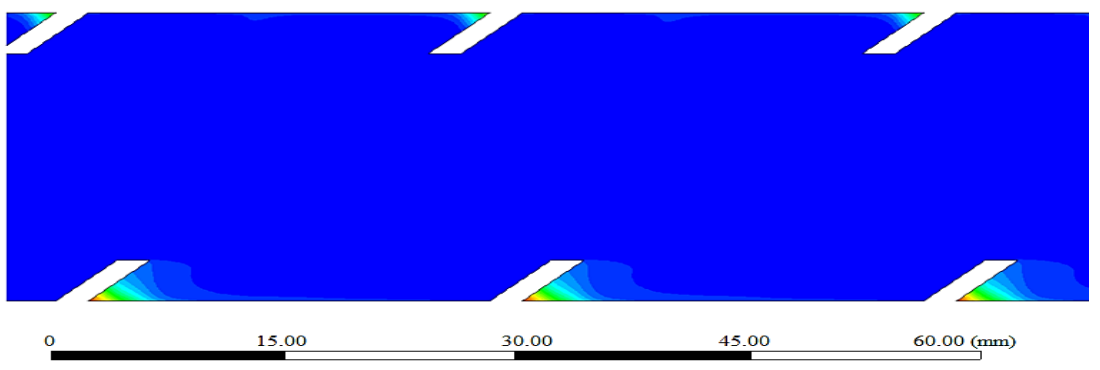

(a)
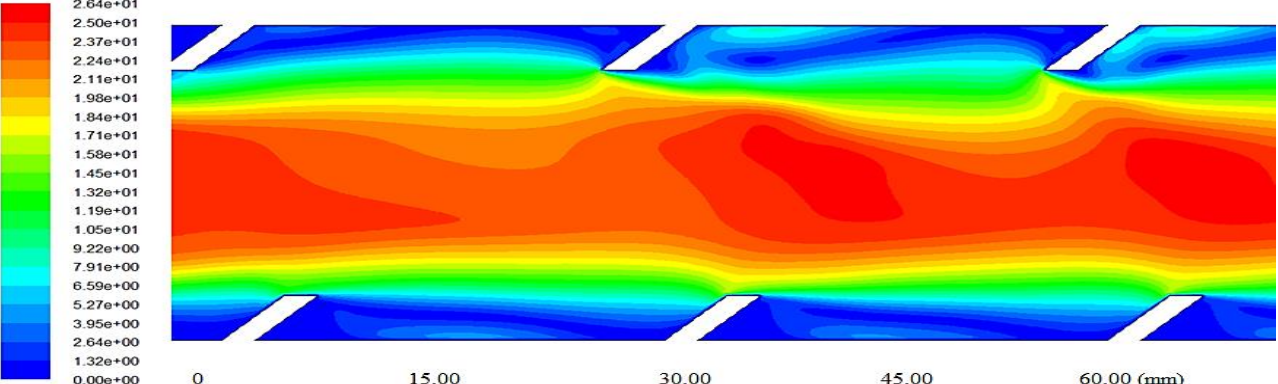

$00 \mathrm{e}+00$
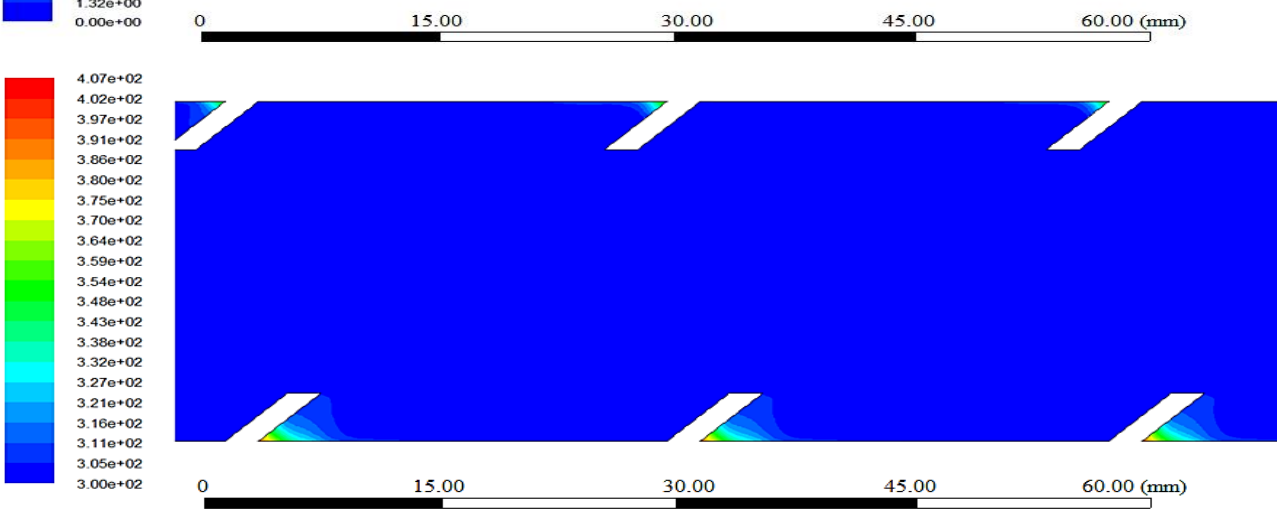

(b) 

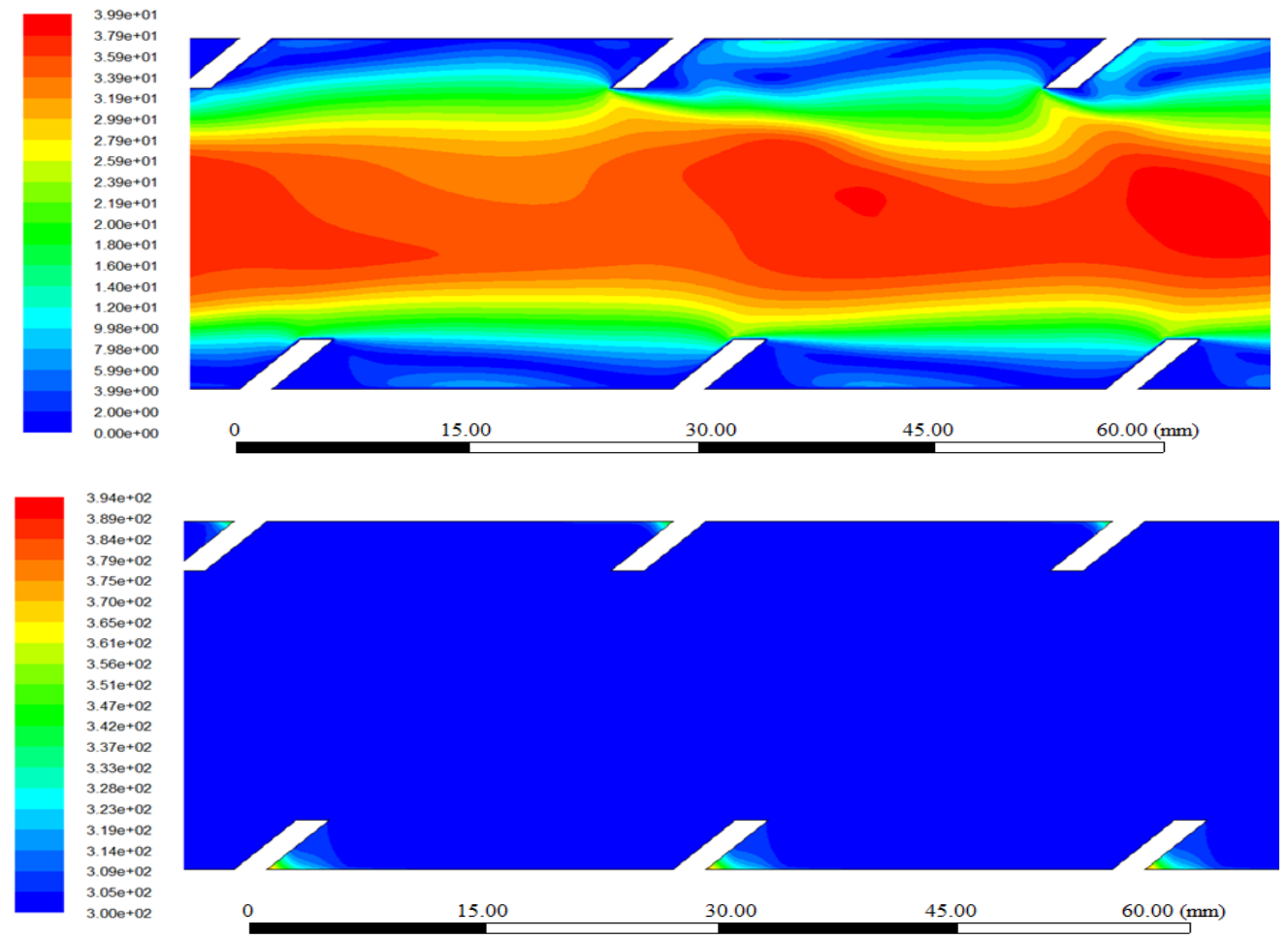

(c)

Figure 7. Velocity (top) and temperature (bottom) at $\mathrm{Re}=7500, \mathrm{~S}=30 \mathrm{~mm}$; (a) $\alpha=45^{\circ}$, (b) $\alpha=35^{\circ}$ and (c) $\alpha=25^{\circ}$.

\section{CONCLUSIONS}

In the study, the use of the inserted rods in double pipe heat exchanger was employed in enhancing the convective heat transfer of turbulent flow within a tube with a circular shape with continuous heat flux on the bottom and top walls. For the acquisition of the coefficient of skin friction, Nusselt number, and performance evaluation criterion, the use of numerical simulation was employed. Based on the findings of the study, the following conclusions are drawn:

1. An augmentation of the Nusselt number was done through the use of rod insert in a double pipe heat exchanger.

2. As an increase occurs in slant angle, an increase occurs in the Nusselt number. It was showed that the max value of average the number of Nusselt was achieved at a slant angle of $45^{\circ}$ of rod insert.

3. The use of rod inserted in a tube at $\left(\alpha=45^{\circ}\right)$ and $(\mathrm{S}=30 \mathrm{~mm})$ was employed in determining the highest coefficient of skin friction. This is because the resistance of larger flow using rod inserts was observed at the larger slant angle.

4. The maximal values of the PEC were found in case of the min angle of $\left(\alpha=25^{\circ}\right)$ and the pitch distance of $\mathrm{S}=30 \mathrm{~mm}$. 


\section{REFERENCES}

[1] Zheng N, Liu P, Shan F, Liu J, Liu Z, Liu W. Numerical studies on thermo-hydraulic characteristics of laminar flow in a heat exchanger tube fitted with vortex rods. International Journal of Thermal Sciences. 2016; 100(1): 448-456.

[2] Fan A, Deng J, Nakayama A, Liu W. Parametric study on turbulent heat transfer and flow characteristics in a circular tube fitted with louvered strip inserts. International Journal of Heat and Mass Transfer. 2012; 55(19-20): 5205-5213

[3] Eiamsa-ard S, Pethkool S, Thianpong C, Promvonge P. Turbulent flow heat transfer and pressure loss in a double pipe heat exchanger with louvered strip inserts. International Communications in Heat and Mass Transfer. 2008; 35(2): 120129.

[4] Aggrey M, Tunde BO, Josua PM. Heat transfer and thermodynamic performance of a parabolic trough receiver with centrally placed perforated plate inserts. Applied Energy. 2014; 136(2): 989-1003.

[5] Jian G, Yuexiang Y, Wei L, Fangming J, Aiwu F. Effects of upwind area of tube inserts on heat transfer and flow resistance characteristics of turbulent flow. Experimental Thermal and Fluid Science. 2013;48(1): 147-155.

[6] Ahmad A, Masoud D. An experimental comparison of convective heat transfer and friction factor of $\mathrm{Al}_{2} \mathrm{O}_{3}$ nanofluids in a tube with and without butterfly tube inserts. Journal of the Taiwan Institute of Chemical Engineers. 2015; 52(3): 31-39.

[7] Mohammed H, Husam H, Wahid M. Heat transfer enhancement of nanofluids in a double pipe heat exchanger with louvered strip inserts. International Communications in Heat and Mass Transfer. 2013; 40(4): 36-46.

[8] Shabanian R, Rahimi M, Shahhosseini M, Alsairafi A. CFD and experimental studies on heat transfer enhancement in an air cooler equipped with different tube inserts. International Communications in Heat and Mass Transfer. 2011; 38(3): 383390.

[9] Tu W, Tang Y, Zhou B, Lu L. Experimental studies on heat transfer and friction factor characteristics of turbulent flow through a circular tube with small pipe inserts. International Communications in Heat and Mass Transfer. 2014; 56(1): 1-7.

[10] Pourramezan M, Ajam H. Modeling for thermal augmentation of turbulent flow in a circular tube fitted with twisted conical strip inserts. Applied Thermal Engineering. 2016; 105(1): 509-518.

[11] Mashayekhi R, Khodabandeh E, Bahiraei M, Bahrami L, Toghraie D, Akbari A. Application of a novel conical strip insert to improve the efficacy of water-Ag nanofluid for utilization in thermal systems: a two-phase simulation. Energy Conversion and Management. 2017; 151(2): 573-586.

[12] Pengxiao L, Zhichun L, Wei L, Gang C. Numerical study on heat transfer enhancement characteristics of tube inserted with centrally hollow narrow twisted tapes. International Journal of Heat and Mass Transfer. 2015; 88(1): 481-491.

[13] Fabio K, Taye M, Gherhardt R. A new model for flow boiling heat transfer coefficient inside horizontal tubes with twisted-tape inserts. International journal of Refrigeration. 2016; 61(1): 55-68.

[14] Erika RI , Maritza E. Cervantes-Gaxiola , Eusiel Rubio-Castro , Jos Ponce-Ortega, Marcos Gonz_alez-Llanes, Cuauht_emoc Reyes-Moreno ,Oscar M. Heat transfer 
analysis of a non-Newtonian fluid flowing through a circular tube with twisted tape inserts. Applied Thermal Engineering. 2015;84(3): 225-236.

[15] Liu P, Zheng N, Shan F, Liu Z, Liu W. An experimental and numerical study on the laminar heat transfer and flow characteristics of a circular tube fitted with multiple conical strips inserts. International Journal of Heat and Mass Transfer. 2018; 117(1): 691-709.

[16] Subhankar S, Sujoy KS. Enhancement of heat transfer of laminar flow of viscous oil through a circular tube having integral helical rib roughness and fitted with helical screw-tapes. Experimental Thermal and Fluid Science. 2013; 47(1): 81-89.

[17] Bhuiya MMK, Ahamed JU, Chowdhury MSU, Sarkar MAR, Salam B, Saidur R, Masjuki HH, Kalam MA. Heat transfer enhancement and development of correlation for turbulent flow through a tube with triple helical tape inserts. International Communications in Heat and Mass Transfer. 2012; 39(1): 94-101

[18] Anvari AR, Javaherdeh K, Emami-Meibodi M, Rashidi AM. Numerical and experimental investigation of heat transfer behavior in a round tube with the special conical ring inserts. Energy Conversion and Management. 2014; 88(2): 214-217.

[19] Bodius S, Sumana B, Shuvra S, Muhammad MK . Heat transfer enhancement in a tube using rectangular-cut twisted tape Insert. Procedia Engineering. 2013; 56(1): 96103.

[20] Sombat T, Yingyong K, Sompol S, Pongjet P. Heat transfer enhancement in tubular heat exchanger with double V-ribbed twisted-tapes. Case Studies in Thermal Engineering. 2016; 7(2): 14-24.

[21] Durand LB, Guimarães JC, Monteiro J, Baratieri LN. Modeling and validation of a 3D premolar for finite element analysis. Revista de Odontologia da UNESP. 2016; 45(1): 21-26.

[22] Ghori MV, Kirar RK. Numerical analysis of tube-fin heat exchanger using fluent. International Journal on Theoretical and Applied Research in Mechanical Engineering. 2012;1(2):37-44.

[23] Ahsan M. Prediction of gasoline yield in a fluid catalytic cracking (FCC) riser using k-epsilon turbulence and 4-lump kinetic models: A computational fluid dynamics (CFD) approach. Journal of King Saud University-Engineering Sciences. 2015;27(2):130-136.

[24] Severo DS, Gusberti VA. modelling approach to estimate bath and metal heat transfer coefficients. In Essential Readings in Light Metals. 2016;2(1): 309-314. 